\title{
Analysis of the Related Countermeasures of Sports Professional Teaching Under the Background of General Teaching
}

\author{
Qinan Zhao \\ Xi'an International University, Xi'an, 710077, China
}

\begin{abstract}
Keywords: Sports specialized teaching, Sports general course teaching, Countermeasures, Analysis
\end{abstract}

\begin{abstract}
The article on the study of college students' sports general course teaching actual effect in the process, the advanced idea of the specialization of physical education reform at home and abroad, the corresponding reference and efficient new as a specific research object, mainly in the form of class experimental teaching and questionnaire survey, summed up the final conclusion, namely the sports teaching in colleges and universities need to combine with specialized elements. The general sports courses mainly is the development direction of the teaching content more rich diversity, and the teaching method and means more human, have fun, to sports performance evaluation method is more scientific. Special teaching can make the teaching content of the professional degree and the depth of the study are improved effectively, and special sports general class practice content not only can better improve the body quality of contemporary college students themselves, with its novel selectivity of diverse teaching methods, and can effectively improve the students' interests in learning. At the same time, fitness testing could also help students to establish their individual sports quality files, and then drive to achieve the goal of health education of college students.
\end{abstract}

\section{The research background of sports general specialized teaching}

In the process of rapid social and economic development in our country, but people's own physical quality drops, and in colleges and universities, the sub-health population scale expanding gradually. It can be found in the physical test results of recent years, juvenile physical decline year by year, and after the youth to enter colleges and universities, the problem is widespread in the colleges and universities. With the expansion of the scale of higher education, students sports foundation polarized increasingly serious, the differences between individual is different, this also gradually become the universities sports teaching focus on the problem.

At present, most of the colleges and universities sports teaching time is two years, and the main teaching content is badminton, basketball, volleyball and so on regular exercise. Sports theoretical teaching content is health care and sports exercise method and its function and value, etc. The physical education curriculum Settings have been unable to meet the requirements of the present personnel training, and teaching form is single and boring, and relatively stringent, obsolete teaching content and also too much emphasis on teachers' leading role, make the students principal role cannot be get play, eventually led to the decrease of the student's study enthusiasm, it is difficult to achieve the goal of the new personnel training ${ }^{[1]}$.

To cultivate professional talent, we must rely on the basis of sports teaching, the university's basic course is the general sports courses. However, in recent years, colleges and universities sports general lessons for pay more attention to teaching, and then played down the professional, for engineering college students pay more attention to the cultivation of the humanities, and the concept of general education and the combination of school curriculum and teaching reform, through sports, general education of university undergraduate course education to carry on the design.

Although the general course and specialized recess contradiction, but the reform of the specialization of the male body is mainly to improve the students' physique as the foundation, the ultimate goal is to strengthen students' basic quality by using the method of specialization, make its interest in physical exercise, and through the specialized teaching methods to achieve the goal of improving students'. And one year in the university sports general course teaching is to better 
implement the specialized teaching. We have certain challenging due to the reform of the public sports professional, so, need more from the reality of school, in the actual teaching of sports actively looking for college sports organic combination between general education and specialized teaching pattern.

\section{The research object and methods}

\section{The research object}

Research object selection college freshman, and carries on the general sports courses teaching and special course experience.

\section{The research methods}

Questionnaire survey

Undergraduates as a key research object, on the special experience of teaching content and general course teaching. Undergraduate new students of the first semester will take the form of sports general course teaching, and for the teaching contents, means and the effect of the classroom, etc. to design the content of the questionnaire. This questionnaire survey is based on random sampling survey method, selecting 1000 undergraduates, and in the process of sampling, completely according to the probability sampling method, including men and women in the selected samples, due to the content of the investigation is the general, therefore, need not consider gender distinction.

\section{Classroom experiment method}

Implemented in the process of classroom teaching and students' interaction, and we will advise to students in the process of learning experience and opinions for consultation. In addition, outside the classroom, can let the students fill in the questionnaire, and write the related study summary report, through different ways to experiment on the effects of physical education teaching and improve ${ }^{[2]}$.

\section{The analysis of the results of the study}

\section{Sports general course satisfaction survey analysis}

Because of undergraduate sports general class content is extensive, so choose ten aspects of survey content, to study college students for the general sports courses evaluation and understanding. Rating is divided into five categories, namely, satisfied, satisfied, general, not satisfied with, and are not satisfied, while scores as 5 points, 4 points, three points, 2 points, 1 point. The average scores of all subjects in a project called "satisfaction", so the three points belongs to the neutral evaluation, and do not meet the three part is defined as a negative attitude, above three points is defined as a positive attitude, as a result, the higher the score, the higher the degree of satisfaction.

In the actual survey results, it can be summarized in the following two points: first, from the overall perspective, the students of physical education curriculum setting is approved, and from ten aspects of the content of the investigation results, only one evaluation hasn't been attained three points. Second, analyze the satisfaction of the rankings can be found, ranking in the front is a directional cross-country and swimming teaching, and the last is the sports teaching theory, the main reason is the single theory class teaching content boring, and the experience of specialized course arrangement is also very single, unable to meet the demand of students' interest in their own. The morning exercises arrangement is satisfaction ranked the second project, this morning exercises exercise in the form of always is not accepted by students.

\section{The analysis of the university freshmen teaching experiment result}

Based on the actual investigation and study, it found that the highest satisfaction is sports teaching content and density. In the actual classroom teaching, the sports classroom teaching in the 90th minute, the density of its movement is only 20 minutes of running, and the rest of the time is for sports theory of knowledge interpretation and analysis. For sports general class of classroom teaching methods, students are not approved, so the satisfaction in the ranking. In the actual classroom teaching of sports, the general teaching of directional cross-country, PE teachers by the 
great physiological load of exercise run once only to control the strength of the student movement, the movement density is small, and the teaching content is less. Therefore, physical education teachers should enrich classroom teaching content, and practice of innovative quality. Directional cross-country teaching as an example, though, all the students exercise amount to mark, but students in the class to run, so after a long time of the training, students can produce a tired of emotions, make them lose interest for directional cross-country learning of the course content.

Above problems were the main reasons, directional cross-country is important content in sports scores, need time to quantify the fraction, arouse the enthusiasm of the students on the surface, but, in fact, students in the course of classroom teaching mode is not recognized ${ }^{[3]}$.However, in order to get satisfied sports scores, students must to cooperate. Therefore, in view of the above phenomenon needs to be in-depth reflection, in setting and appraisal method, the content of classroom teaching methods also need to adjust.

\section{Discussion and Analysis}

\section{Problems which found in directional cross-country}

The class as a unit and uniform directional cross-country content, map of sending students in class and has the memory function of $\mathrm{CH}$ refers to the card, and electronic clock timing system.PE teachers need to introduce students to the specific methods, tries to remove card information, and adopt the method of partial set out. The starting point should clock in, then according to the map and clock in order to find the task point. Among them, the boy's task is ten, girls for eight, distance is about $1800-2200 \mathrm{~m}$. Normal levels take 20 minutes to complete the task, the faster can be done in 15 minutes, while keeping the close to 30 minutes, if not done in 30 minutes, you need directly back to the finish.

According to the time to finish the task to evaluate students' grades, although this method can effectively arouse the enthusiasm of the students run, however, in actual practice will still exist many problems in the process. First, students will produce psychological aversion, reduces the number of students enrolled directional cross-country constantly. Second, in the setting of course there is a certain risk, because the route distance is longer, and after the main, jungles, and buildings, so the physical education teachers cannot undertake to the student effectively control, if the student accidents occurred in the process of running, is cannot be found and treated in time, there is a certain hidden trouble of security[4].

Therefore, in order to effectively solve the potential safety hazard, it needs to change course content setting. In the aspect of map content, need to choose according to the state of school geography position more easily to control. At the same time, can use English to set goals and tasks of corresponding points of knowledge, but also needs to find the first point to clear the second distance and location. In addition, you can set up some more complex site to endurance training for students, set up corresponding obstacles in along the way, which further increases the difficulty. For some students, physical education teachers can also add some exercise physical quality practice project, like push-ups or leapfrog and so on.

For the final examination work also need to change, the original method can be as one of the standard grades. For long distance endurance better students, need to improve the classroom physical training standards, according to the quality of the finish time quantity to classify the performance standard. Therefore, we need to make a different marking scheme, to ensure that students can better participate in the sports teaching.

\section{Other content questions and discussion}

Through a course to undertake to the student physique test is not reasonable, it will make more inaccurate data. And undergraduates physical foundation is relatively poor, so, should be changed into two classes of physical fitness test, and test the content of the need to test by teachers, at the same time for the student to establish quality information archives, the physique test not qualified students, need targeted training and training.

Physical tests need to be in undergraduate second year second semester test again, and the third test before graduation. At the same time, according to the actual test results are needed to formulate 
specific sports teaching planning, make students form the habit of lifelong exercise, thus to improve the students' physical quality.

Because experience lesson is unable to meet their own interests, so, only pay attention to special sports teachers' teaching, students need to free choice, and participate in the project itself like experience.

\section{General teaching ideas and Suggestions based on the sports specialized teaching}

Article focuses on the problem is that the development of the sports general course teaching, therefore, in terms of the general sports courses setting need to fully consider the cultivation of students' fitness consciousness, and attention to the development of the physical quality and the effect of classroom practical exercise, so that the students can get into the habit of lifelong physical exercise, and fully understand the meaning of fitness ${ }^{[5]}$.So, in order to achieve the above goals, it needs to fully reflected in the actual teaching content, improve the students' interest in physical education learning. After comprehensive analysis and research, finally to undergraduate student, grade 2 of special sports, as the key to the professional training in teaching, make student's physical quality and the sports specialized quality enhances unceasingly, thus improving national quality. Also need to reflect in the process of assessment of the actual project characteristics and individual differences, so that the students can through the efforts to achieve goals. It must understand and master, and to the student carries on the inspection of sports knowledge and ability, thus effectively motivate and encourage students to be more actively involved in the sports teaching.

In addition, active participation and should be happy to participate in sports as a guide to sports teaching goal. A striking feature of sports education is active sports and happiness. Students should participate in sports activities in the process of fully display its own fitness, thoughts and wisdom, and success and failure of emotional experience, finally enjoy the satisfaction of sports activities. At the same time, students in the healthy sports activities can also betray the emotions as far as possible, so that it is fully enjoy the charm of sports itself. In addition, sports teaching need to be combined with students characteristics, through the different teaching methods and teaching content arrangement, and organized to the implementation of teaching, better achieve the teaching goal in the happy sports, eventually make students' body quality and mood are perfected. Also only in this way, to be able to make the students actively participate in sports activities, into the physical exercise.

\section{Conclusion}

To sum up, college students' sports general course teaching in college physical education course occupies the important position, and it plays an important role. Therefore, in the process of sports general teaching more need to perfect and enrich the teaching content, and improve classroom teaching methods, to enable students to take an interest in physical education teaching, more actively participate in sports activities, to improve students' body quality.

\section{References}

[1] Wang Yong. Sports professional teaching under the background of general course teaching research. Journal of style products and technology,2014(21):69-70,60.

[2] Chai Jiao, Zheng Fengjia, Li Linpeng, etc. Subject teaching knowledge to the cultivation of PE teachers' professional way to study. Journal of xi 'an sports institute,2011,28(3):363-366.

[3] Cao Yonglin, Chang Naijun, Ge Zhenbin, etc. The investigation of present situation of ordinary university sports teachers' specialization. Journal of sports research and education,2011,26(5):63-65. 
[4] Zhang Yujia, Fan Kai. Public physical education teachers in colleges and universities specialized level thinking. Journal of Chengde medical college,2014(3):276-277.

[5] Wang Junqing. It should deepen the reform of sports in common colleges and universities, and reform of physical education curriculum system. Journal of Hebei enterprises,2013(11):74-74. 